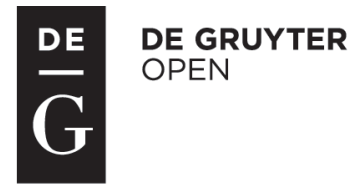

\title{
EVALUATION OF THE TECHNOLOGICAL SUITABILITY OF BEEF MUSCLES: M. SEMITENDINOSUS, M. SEMIMEMBRANOSUS, MM. PSOAS MAJOR AND MINOR AS ENTIRE PRIMAL CUTS IN THE PRODUCTION OF RAW FERMENTED MEATS WITH REGARD TO THE RAW PORK PRODUCTS*
}

\author{
Ewelina Węsierska \\ Department of Animal Product Technology, University of Agriculture in Krakow, Poland \\ Balicka 122, 30-149 Kraków, Poland \\ Corresponding author: e.wesierska@ur.krakow.pl
}

\begin{abstract}
The aim of the study was to evaluate the technological suitability of selected beef muscles: m. semitendinosus (BST), m. semimembranosus (BSM), mm. psoas major and minor (BPM) as entire primal cuts in the production of raw fermented meats, compared to the raw pork rump (RSR) and loin (RSL), widely known in the Podlasie region. The 4-week maturation was conducted by the same traditional method in a genuine ripening room, and the texture, colour and sensory parameters of the pork and beef products were compared. The lowest water activity $(0.89$ and 0.83$), \mathrm{pH}$ (5.16 and 4.75) as well as the highest WB shear force $\left(8.50\right.$ and $\left.19.96 \mathrm{kG} / \mathrm{cm}^{2}\right)$ and TPA hardness (52.12 and 199.24 N) were found in the ready-to-eat RSL and BST, respectively. The RSR and BPM were characterized by the lowest values of WB shear force $\left(7.63\right.$ and $\left.9.49 \mathrm{kG} / \mathrm{cm}^{2}\right)$, TPA hardness $(48.17$ and $105.18 \mathrm{~N})$ and TPA chewiness (8.39 and $32.68 \mathrm{~N})$, as well as the highest grades for overall impression $(4.50 \mathrm{pts})$, cross-section colour $(4.60 \mathrm{pts})$, structure $(4.60 \mathrm{pts})$, tenderness $(4.30$ and $4.70 \mathrm{pts})$ and flavour desirability (4.60 pts) in the sensory evaluation while the RSL and BPM were the juiciest (4.60 and $4.70 \mathrm{pts})$. The $\mathrm{a}^{*}$ values and chroma showed an increase in redness during the first 2 weeks of beef aging and during the entire aging period in the pork products. The most significant colour differences were found for BSM, BST and BPM products $\left(\triangle E L{ }^{*} a^{*} b^{*}=6.48,5.27\right.$ and 4.24 , respectively).
\end{abstract}

Key words: beef, pork, ripening, texture, colour, sensory evaluation

Raw ripened meat products have become one of the more important components of the human diet in Central Europe, including Poland. They are formed as a result of complex biochemical and physical processes. The physical transformation of

\footnotetext{
*This work has been supported by the Polish Committee of Scientific Research (Grant No. NN312305740).
} 
meat into the ready-to-eat products is mainly due to the partial dehydration during ripening with a range of 1 week to 1.5 year. The prices for reputable European groceries are still excessive for most consumers but the unique sensory quality and the novelty value associated with the probiotic aspects introduce a new angle of perception (Flores and Toldrá al., 2011; Kołożyn-Krajewska and Dolatowski, 2012). The consumption of spontaneously fermented meats based on traditional recipes has become fashionable and is an important tool for stimulating the development of poorer farming regions. The regional products of Italy, Spain, Portugal, France and recently even the Czech Republic are very well described in scientific literature for the development of enzymatic and ageing processes dependent on salt concentration, time of ripening and microflora activity (Salgado et al., 2005; Rason et al., 2007; Roseiro et al., 2008; Spaziani et al., 2009; Benedini et al., 2012; Laureati et al., 2014). Podlasie represents one of few regions in Poland where the tradition of producing cured or uncured cold meats and sausages is still observed but the products are unknown. Today's production of cold meats from raw ripened meat products in the Podlasie region follows the old Lithuanian school with pork as the core ingredient. Raw cold meats are produced from the gammon, shoulder, neck and loin. The manner of salting (dry-salting or pickle-curing), the time of cold smoking (from 10 days up to 3 weeks), the selection of spices (black pepper, allspice, coriander, bay leaves, garlic, cloves) and additives (saltpetre, sugar or honey), and insect-prevention methods used during the month-long curing process (wrapping the meat in tissue-thin linen), all depend on the individual formula and technology transferred from generation to generation in families.

The aim of this study was to evaluate the technological suitability of the selected beef muscles as entire primal cuts in the production of raw fermented products, compared to the raw pork rump and loin, popular and widely known in the Podlasie region. It proved reasonable to analyse the following beef muscles: $m$. semitendinosus, $m$. semimembranosus and mm. psoas major and minor due to the differences in their chemical composition, texture attributes and other qualitative properties, variable during the postmortem cold ageing (Koohmaraie et al., 1988; Klont et al., 1998; Lefaucheur and Gerrard, 2000; Kołczak et al., 2005; Kołczak et al., 2008). The principal idea was to perform the aging process with the same traditional method, using a genuine ripening room, and to compare the texture, colour and sensory parameters of both the pork and beef products before, during and after processing.

\section{Material and methods}

\section{Processed meat products}

The quality of the seven raw meat products, ripened over a period of 4 weeks was estimated. Two pork products were produced from ham hock (RSR) and sirloin (RSL) as individual units of the Polish Landrace breed primal cuts. The RSR consisted of the following muscles: gluteus medius, gluteus superficialis, end of longissimus, and a piece of the biceps femoris with about a $5 \mathrm{~mm}$ thick fat cover. The RSL 
was constituted as a uniform tissue of $m$. longissimus dorsi. Three beef products were obtained from 18-month-old cows of the Black-and-White breed and ripened as entire primal cuts of $m$. semitendinosus (BST), m. semimembranosus (BSM), mm. psoas major and minor (BPM). The meat and spices were obtained from local producers (from the Podlasie region in Poland). The production was conducted using traditional method in a genuine ripening room of regional producers to maintain the original conditions of fermentation. The smoking procedures and spice compositions were kept confidential. The meat cuts were preserved by dry salting (non-iodized rock salt) and seasoned for one week in cool storage premises at $4-7^{\circ} \mathrm{C}$. Nitrite curing was not practised. The excess salt was removed by drenching for about $24 \mathrm{~h}$ (the intended salt content after salting process was about $3.5 \%$ ). The primal cuts were turned over during the salting, soaking and washing processes. After draining, the products were smoked with a cold smoke and ripened at $18-20^{\circ} \mathrm{C}$ for 1 week and then at $12-15^{\circ} \mathrm{C}$ for a further 3 weeks in a ripening room with a relative humidity of $80-85 \%$. Three production batches were carried out. Three products, as the replications in each batch were studied, after they were wrapped in a greaseproof paper, packed into thermo-insulated bags in cooling conditions $\left(4-6^{\circ} \mathrm{C}\right)$ and immediately shipped by courier to a laboratory for analysis within $24 \mathrm{~h}$.

\section{Sampling}

Samples of the raw meats were collected just before the smoking procedures, after dry salting (ripening period: 0 ). The cuts were also sampled at different times throughout the ripening process (after the 2 nd and 4 th week of ripening). After separating the material for colour and sensory analysis (the latter only for the ready-to-eat products), Warner-Bratzler (WB) shear force, texture profile analysis (TPA), water activity $\left(\mathrm{a}_{\mathrm{w}}\right)$ and $\mathrm{pH}$ were estimated. After removing the casing, the remainder was cut or comminuted using, respectively, a cork borer or a kitchen blender (Multiquick Professional, Braun) to obtain representative raw meat samples for the appropriate investigations. The collected samples were analysed immediately according to the appropriate methods.

\section{Analysis}

The WB shear force was determined using seven cylindrical samples measuring $14 \mathrm{~mm}$ in diameter and $15 \mathrm{~mm}$ in length. The measurements were carried out for samples cut perpendicular to the fibre direction using a texturometer TA-XT2 (Stable Micro Systems, UK) and a Warner-Bratzler knife with a triangular cut-out. The TPA analysis was conducted as described by Breene (1975) using a TA-XT2 texture analyser with a $50 \mathrm{~mm}$ diameter cylindrical probe. Muscle samples (14 $\mathrm{mm}$ in diameter and $10 \mathrm{~mm}$ in length), cut lengthwise to the fibres, were compressed twice, parallel to the fibre direction to $70 \%$ of their original height at a crosshead speed of 5 $\mathrm{mm} / \mathrm{s}$ (before testing) and $2 \mathrm{~mm} / \mathrm{s}$ (during and after testing), with a 3 second interval between the first and second stroke. The TPA parameters of hardness and chewiness were chosen. Each measurement of the WB shear force and the TPA parameters was repeated seven times. The results of the measurements were compiled with the use of the Stable Micro Systems Texture Expert software for Windows, version 1.05. 
A measurement of the water activity (LabMaster-aw, Novasina) as well as the $\mathrm{pH}$ was performed ( $\mathrm{pH}$-meter $\mathrm{CP}-411$ with a PP-3 electrode, Elmetron). The $\mathrm{pH}$ was measured in a water homogenate, the proportion to mass being 1:3. The Chroma Meter CR-400 with a C illuminant (Minolta) was used for measuring colour differences. CIE $L * a * b *$ system (CIE, 1976) was used for colour measurement. The analyser was calibrated according to the white reference standard $\left(L^{*}=94.2 ; a^{*}=0.3133\right.$; $\left.b^{*}=0.320\right)$. Next the values for coordinates lightness $\left(\mathrm{L}^{*}\right)$, redness $\left(\mathrm{a}^{*}\right)$ and yellowness $\left(\mathrm{b}^{*}\right)$ were determined. Colour difference $\left(\Delta \mathrm{E}_{I^{*} a^{* *} b^{*}}\right)$ between the raw meats and the ready-to-eat products were calculated as $\sqrt{\left(\Delta L^{*}\right)^{2}+\left(\Delta a^{*}\right)^{2}+\left(\Delta b^{*}\right)^{2}}$ and chroma as $\sqrt{\mathrm{a}^{*} 2+\mathrm{b}^{*} 2}$ (Wyszecki and Stiles, 1982). The values of $\Delta \mathrm{E}_{L^{*} a^{*} b^{*}}$ in the range of 3.51-5.00 indicated a noticeable colour difference, higher than 5.00 - a significant difference. Measurements were made on the medial surface of subsequent rashers of meats, after the first one was cut off, to avoid surface discolorations due to possible crust formation. The products were evaluated based on a 5-point scale which assumed the following levels of quality: 4.51-5.00 (very good); 3.51-4.50 (good); 2.51-3.50 (satisfactory); 1.00-2.50 (unsatisfactory). The evaluation was carried out on the final products only (4 week). To rate the overall evaluation, the features were assigned the following significance coefficients: 0.05 (overall impression), 0.05 (cross-section colour), 0.10 (cross-section structure), 0.10 (odour intensity), 0.10 (odour desirability), 0.15 (juiciness), 0.15 (tenderness), 0.10 (saltiness), 0.10 (flavour intensity), 0.10 (flavour desirability). The sessions were held at 11 a.m., $3 \mathrm{~h}$ after breakfast. The slices were prepared for members as described by Martin et al. (2008). The statistical analysis was performed using the Statistica software for Windows, version 9.0. The effect of the kind of products and the time of ripening on the physico-chemical and sensory properties was tested by the analysis of variance (ANOVA) with one factor: the ripening period (levels: weeks $0,2,4)$ and two factors: the ripening period (levels: 0, 2, 4) and the type of product (levels: RSR, RSL and BST, BSM, BPM). The Scheffe and Duncan post-hoc tests were used for the comparison of means (the significance of differences was investigated at $\mathrm{P}<0.05)$.

\section{Results}

The changes of the WB shear force, texture parameters, water activity and $\mathrm{pH}$ of the pork and beef products during ripening are presented in Tables 1 and 2. As a consequence of evenly slight drying, the hardness of the pork and beef products increased. In the case of the pork, the lowest $\mathrm{a}_{\mathrm{w}}(0.89)$ and the highest WB shear force and TPA hardness values, $8.50 \mathrm{kG} / \mathrm{cm}^{2}$ and $52.12 \mathrm{~N}$, respectively, were indicated in the ready-to-eat RSL. For comparison, in the group of beef products the lowest $\mathrm{a}_{\mathrm{w}}(0.83)$ and the highest WB shear force and TPA hardness values, $19.96 \mathrm{kG} / \mathrm{cm}^{2}$ and 199.24 N, respectively, were indicated in the ready-to-eat BST. The changes of WB shear force, texture parameters and $\mathrm{a}_{\mathrm{w}}$ values during ripening were statistically significant for both the pork and beef groups of products. The values of $\mathrm{pH}$ decreased significantly during the ripening of beef products, from 5.86 to 4.75 in BST, from 
5.84 to 5.09 in BSM, and from 5.64 to 4.82 in BPM. The difference between raw materials and ready-to-eat pork product was significant for RSL with final $\mathrm{pH}$ of 5.16. The ready-to-eat RSR assumed the shape of an irregular cone and had a darkred meat colour on the surface and a pink-red colour on the cross-section, whereas the fat colour was white. The meat of RSL was pink to red with a shade of gold on the surface and pink to red on the cross-section. The ready-to-eat BST, BSM and BPM products assumed the shape of a flattened cylinder and were characterised by a soft, resilient consistency. The meat was pink to red on the cross-section. The colour differences of the pork and beef products occurring during ripening are presented in Tables 3 and 4 as the CIE $L * a * b *$ variable values. Independently of slight drying, the surface of the pork and beef products was moist and strongly reflected the light, so the $L^{*}$ values significantly increased during the ripening period. On the grounds of the $a^{*}$ values increase, the chroma showed an increase of the red colour intensity during the first 2 weeks of ripening in the beef products (from 26.62 to $28.75, \mathrm{P}<0.05$ ), and for the duration of the entire processing period in the pork products (from 26.10 to 29.00, $\mathrm{P}<0.05$ ). The values of $\Delta \mathrm{E}_{L^{*} a^{*} b^{*}}$ achieved the levels from 1.75 (RSR) to 6.48 (BSM) in the final products and the most substantial differences between the initial and final colour $\left(\Delta \mathrm{E}_{L^{*} a^{*} b^{*}}>5.00\right)$ were indicated in the BST and BSM. The sensory analysis of the ready-to-eat products showed that RSR and BPM were preferred by the panel over the other selections (Table 5). Both meats obtained the highest grades for the overall impression (4.50 pts), cross-section colour (4.60 pts), cross-section structure (4.60 pts), tenderness (4.30 and $4.70 \mathrm{pts}$ ) and flavour desirability (4.60 pts). The overall quality of all the analysed products was determined by the cross-section colour as well as the hardness and was estimated at a good level (4.20-4.50 pts). The RSL and BPM were the juiciest (4.60 and 4.70 pts). In accordance with the opinion of the panel of judges, the products did not differ in terms of the overall impression, saltiness as well as odour and flavour intensity. The flavour of the products was salty, characteristic of raw fermented meats, dependent on the variety and proportions of spices used (the aroma of bay leaf, pepper and juniper was distinguishable).

Table 1. Influence of ripening on WB shear force, TPA hardness and TPA chewiness of RSR and RSL products (mean, standard deviation, $\mathrm{n}=3$ )

\begin{tabular}{c|c|c|c|c|c|c|c|c|c|c|c|c}
\hline Product & \multicolumn{9}{c|}{ RSR } & \multicolumn{5}{c|}{ RSL } \\
\hline $\begin{array}{c}\text { ripening } \\
\text { period (week) }\end{array}$ & \multicolumn{2}{|c|}{0} & \multicolumn{2}{|c|}{2} & \multicolumn{2}{|c}{4} & \multicolumn{2}{|c|}{0} & \multicolumn{2}{|c|}{2} & \multicolumn{2}{c}{4} \\
\hline & M & SD & M & SD & M & SD & M & SD & M & SD & M & SD \\
\hline
\end{tabular}

\begin{tabular}{llllllllllllll}
\hline WB shear force $4.17 \mathrm{a}$ & 0.02 & $6.31 \mathrm{~b}$ & 0.19 & $7.63 \mathrm{c}$ & 0.09 & $5.78 \mathrm{a}$ & 0.08 & $7.78 \mathrm{~b}$ & 0.08 & $8.50 \mathrm{c}$ & 0.01
\end{tabular} $\left(\mathrm{kG} / \mathrm{cm}^{2}\right)$

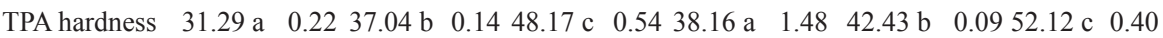
(N)

$\begin{array}{llllllllllllll}\text { TPA chewiness } & 4.27 \text { a } & 0.05 & 6.05 & \mathrm{~b} & 0.07 & 8.39 \mathrm{c} & 0.53 & 5.46 \mathrm{a} & 0.52 & 8.48 \mathrm{~b} & 0.03 & 10.35 \mathrm{c} & 0.05\end{array}$ $(\mathrm{N})$

\begin{tabular}{llllllllllllll}
$\mathrm{a}_{\mathrm{w}}$ & $0.92 \mathrm{a}$ & 0.01 & $0.92 \mathrm{a}$ & 0.01 & $0.90 \mathrm{~b}$ & 0.01 & $0.96 \mathrm{a}$ & 0.01 & $0.90 \mathrm{~b}$ & 0.01 & $0.89 \mathrm{~b}$ & 0.01 \\
$\mathrm{pH}$ & $5.49 \mathrm{a}$ & 0.03 & $5.33 \mathrm{a}$ & 0.04 & $5.27 \mathrm{a}$ & 0.29 & $5.66 \mathrm{a}$ & 0.15 & $5.37 \mathrm{a}$ & 0.19 & $5.16 \mathrm{~b}$ & 0.12 \\
\hline
\end{tabular}

$\mathrm{a}, \mathrm{b}, \mathrm{c}, \mathrm{d}-$ all values in a row with different superscripts are different at $\mathrm{P}<0.05$. 


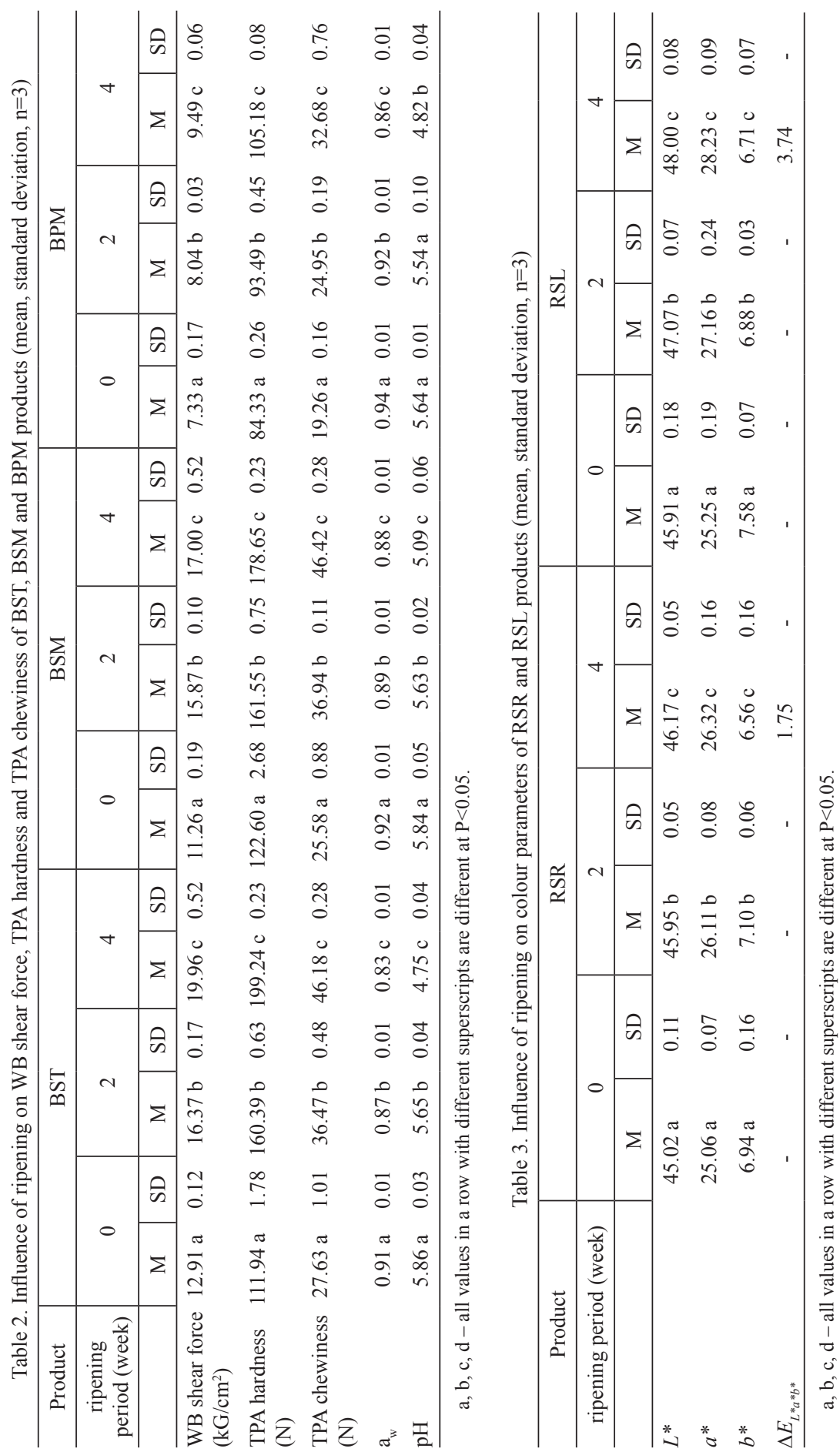




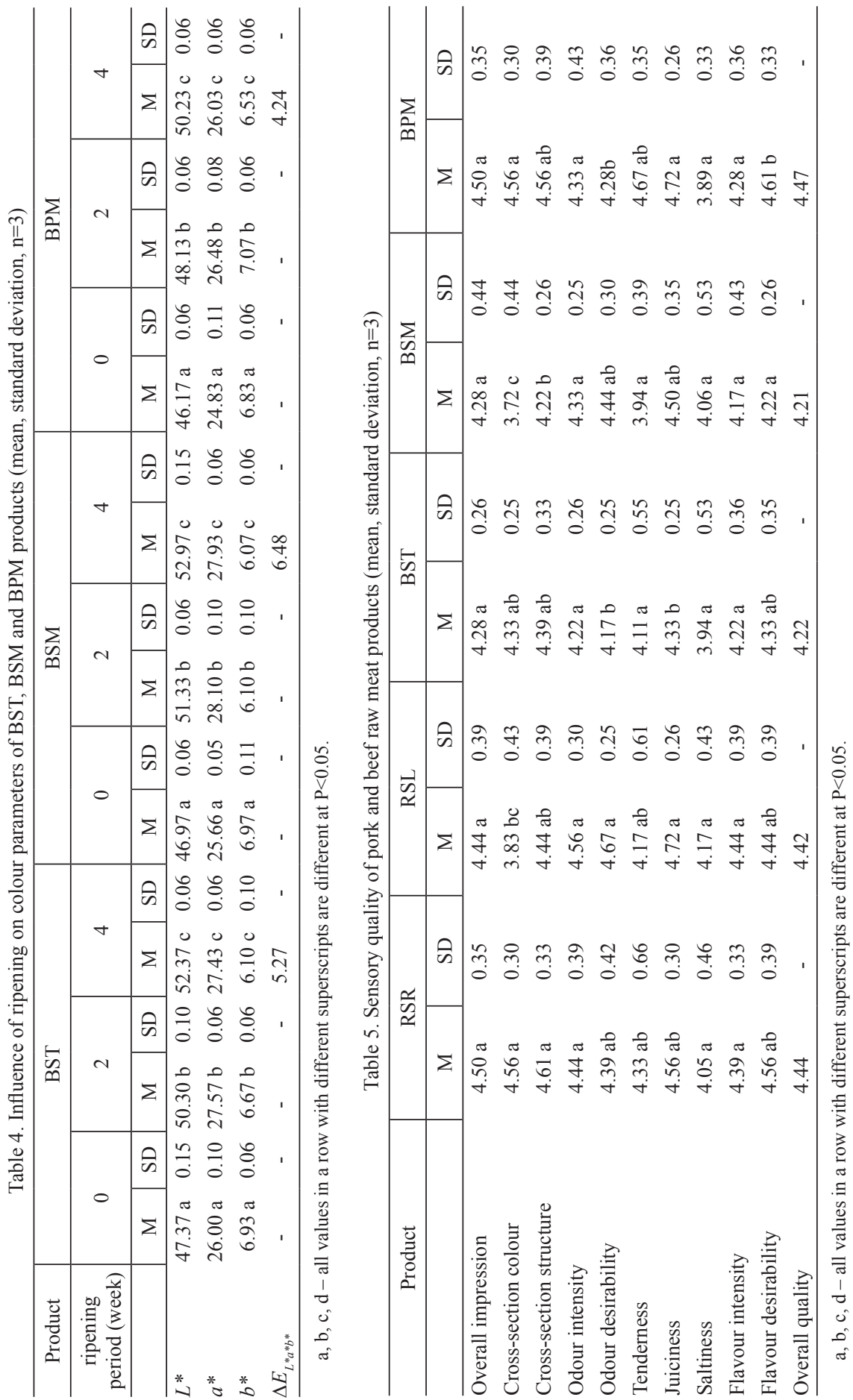




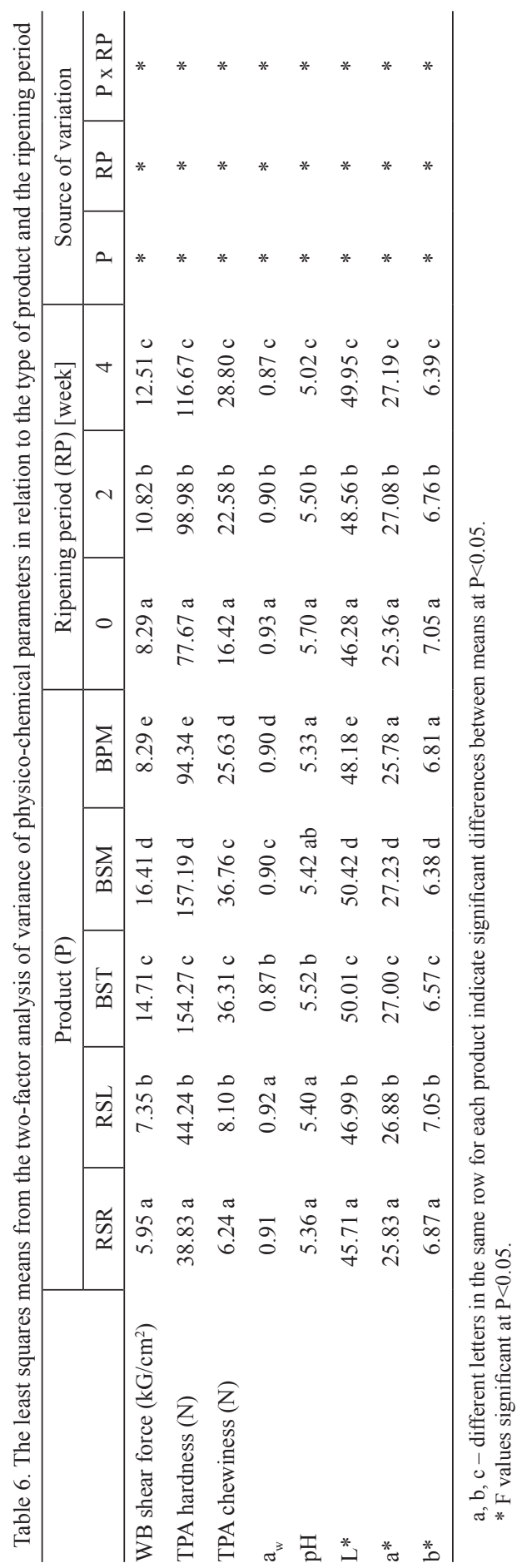


Similar correlations $(\mathrm{P}<0.05)$ for all of examined products between $\mathrm{a}_{\mathrm{w}}$ and the WB shear force, TPA hardness and TPA chewiness (average values: $r=0.62,-0.68$, -0.63 , respectively), $\mathrm{a}_{\mathrm{w}}$ and $\mathrm{CIE}_{L^{*} a^{*} b^{*}}$ (average values: $\mathrm{r}=-0.79,-0.66,0.77$, respectively) as well as $\mathrm{pH}$ and $\mathrm{CIE}_{L^{*} a^{*} b^{*}}$ (average values: $\mathrm{r}=0.49,-0.38,0.52$, respectively) were observed. The results of the two-way analysis of variance (Tables 6 and 7) showed that both factors - the type of product and the ripening period significantly influenced the level of the analysed variables, with the exception of $\mathrm{a}_{\mathrm{w}}$ and $\mathrm{pH}$ of RSR and RSL, TPA chewiness of BST and BSM as well as $\mathrm{a}_{w}$ of BSM and BPM. The interactions between the type of product and the ripening period were significant $(\mathrm{P}<0.05)$ for all attributes.

\section{Discussion}

Serra et al. (2005), Ruiz-Ramírez et al. (2005, 2006), Larrea et al. (2007), Benedini et al. (2012) as well as Laureati et al. (2014) reported that the hardening of raw fermented meat products is due to the water loss during ripening as well as the proteolysis development. The higher salt concentration with lower water activity values inhibit the proteolytic processes, resulting in the production of harder and more fibrous meats. Additionally, according to Serra et al. (2005), the specific crust formation occurs when the raw meats undergo a drying process at a relatively low level of humidity and in a high temperature. The appropriate ripening conditions protected both evaluated groups of products against the crust formation on their lean surfaces, even though the final values of $\mathrm{a}_{\mathrm{w}}$ were in the range of $0.83-0.88$ in beef (BST, BSM, BPM) and 0.89-0.90 in pork (RSR, RSL) products. Węsierska et al. (2013 a) reported that the significantly higher WB shear force and TPA hardness of the fermented meat products is connected with the increase of the protein content that takes place as a consequence of the dehydration phenomena. This would be in agreement with the earlier results for RSL and BST products, which in their groups had higher protein content at the end of ripening: 26.72\% (Węsierska et al., $2013 \mathrm{~b}$ ) and $30.00 \%$ (Węsierska et al., 2014), respectively.

The shorter ripening period and therefore limited drying influenced the higher $L^{*}$ and $a^{*}$ as well as lower $b^{*}$ values obtained in the present study. Carrapiso (2005) found the significant effect of the rearing system on sensory brightness and redness of Iberian hams but not on CIEL $a^{*} b^{*}$. The fact that the sensory panel is more effective than the instrumental colour measurement of the raw meats was also confirmed by other authors (O'Sullivan et al., 2002; Carrapiso et al., 2003). From the analysis of the ingredients, chemical content as well as the sensory quality of traditional raw meat products, Węsierska et al. (2013 a) noted that the most popular smoked products (hams, loins) in terms of odour (3.9-4.4 pts) and flavour (3.7-4.0 pts) have the highest nutritional value of animal protein (30.6-40.6\%) and fat (6.3-12.0\%) as well as the least water (41.8-52.2\%). Additionally, the products described by those authors are characterised by the lowest $\mathrm{a}_{\mathrm{w}}$ values $(0.81-0.86)$ and the greatest TPA hardness (128.6-140.3 N), TPA chewiness (28.9-54.2 N) as well as WB shear force $(4.5-12.9 \mathrm{kG})$. 


\section{Conclusions}

The beef primal cuts of $m$. semitendinosus (BST), m. semimembranosus (BSM) as well as mm. psoas major and minor (BPM) are suitable for raw fermented meats manufacturing despite their significantly higher values of the WB shear force, TPA hardness and TPA chewiness, especially the BPM with the juiciness comparable to that in pork loin (RSL). Moreover, the BPM has a highly valued cross-section colour as well as structure and is considered to be the most tender among the examined products, while the pork rump (RSR) has the best taste in the opinion of the panel members. The meats with the lowest $\mathrm{a}_{\mathrm{w}}$ values show the highest WB shear force, TPA hardness and TPA chewiness values. A properly conducted 4-week ripening period and slight drying protect the products against crust formation and their reflecting, dark-red surfaces remain moist. The increase of the red colour intensity takes place during the first 2 weeks of ripening in beef and for the duration of the manufacturing process in pork products. The colour of the BST and BSM is subject to greater modifications than the BPM, RSR and RSL.

\section{References}

B enedini R., Parolari G., Tos cani T., Virgili R. (2012). Sensory and texture properties of Italian typical dry-cured hams as related to maturation time and salt content. Meat Sci., 90: 431-137.

B re e n e W.M. (1975). Application of texture profile analysis to instrumental food texture evaluation. J. Texture Stud., 6: 53-82.

C a r r a p i s o A.I., G a r c i a C. (2005). Instrumental colour of Iberian ham subcutaneous fat and lean (biceps femoris): Influence of crossbreeding and rearing system. Meat Sci., 71: 284-290.

C a rrapi s o A.I., B onilla F., Garcia C. (2003). Effect of crossbreeding and rearing system on sensory characteristics of Iberian ham. Meat Sci., 65: 623-629.

F lores M., Toldrá F. (2011). Microbial enzymatic activities for improved fermented meats. Food Sci. Technol., 22: 81-90.

K lon t R.E. B rock s L., E i k e le n b o o m G. (1998). Muscle fiber type and meat quality. Meat Sci., 49: 219-229.

K ołc zak T., Pa lka K., Łą cki J. (2005). Water retention, shear force and texture parameters of cattle psoas and semitendinosus muscles unfrozen and frozen during post-mortem ageing. Pol. J. Food Nutr. Sci., 55: 17-26.

K ołc zak T., Krzyszt of orski K., P a lka K. (2008). Effect of post-mortem ageing, method of heating and reheating on collagen solubility, shear force, and texture parameters of bovine muscles. Pol. J. Food Nutr. Sci., 58: 27-32.

Kołożyn-Krajewska D., Dol a towski Z. (2012). Probiotic meat products and human nutrition. Process Biochem., 47: 1761-1772.

Ko ohmarai e M., B abiker A.S., Merkel R.A., Duts on T.R. (1988). Role of Ca2 ${ }^{+}-$dependent proteases and lysosomal enzymes in postmortem changes in bovine skeletal muscle. J. Anim. Sci., 53: 1253-1257.

Larrea V., Pérez-M un uer a I., Hernando I., Qu i les A., L 1 o r c a E., L 1 u c h M.A. (2007). Microstructural changes in Teruel dry-cured ham during processing. Meat Sci., 76: 574-582.

Laureati M., Buratti S., Giovanelli G., Corazzin M., Lo Fiego D.P., Pagliari$n$ i E. (2014). Characterization and differentiation of Italian Parma, San Daniele and Toscano drycured hams: a multi-disciplinary approach. Meat Sci., 96: 288-294.

L e fa u che ur L., Gerrard D. (2000). Muscle fiber plasticity in farm mammals. J. Anim. Sci., 77: $1-19$. 
Martin D., Antequera T., Muriel E., Perez-Palacios T., Ruiz J. (2008). Effect of dietary conjugated linoleic acid in combination with monounsaturated fatty acids on the meat composition and quality traits of dry-cured loin. Meat Sci., 80: 1309-1319.

O' Sullivan M.G., Byrne D.V., Stagsted J., Andersen H.J., Martens M. (2002). Sensory colour assessment of fresh meat from pigs supplemented with iron and vitamin E. Meat Sci., 60: 253-265.

R a s on J., La guet A., B erge P., D u four E., L e b e c que A. (2007). Investigation of the physicochemical and sensory homogeneity of traditional French dry sausages. Meat Sci., 75: 359-370.

Ros eiro L.C., Santos C., Sol M., Borges M.J., Anjos M., Goncalves H., Carval ho A.S. (2008). Proteolysis in Painho de Portalegre dry fermented sausage in relation to ripening time and salt content. Meat Sci., 79: 784-794.

Ruiz-Ramírez J., Arnau J., Serra X., Gou P. (2005). Relationship between water content, $\mathrm{NaCl}$ content, $\mathrm{pH}$ and texture parameters in dry-cured muscles. Meat Sci., 70: 579-587.

Ruiz-Ramírez J., Arnau J., Serra X., Gou P. (2006). Effect of $\mathrm{pH}_{24}, \mathrm{NaCl}$ content and proteolysis on the relationship between water content and texture parameters in biceps femoris and semimembranosus muscles in dry-cured ham. Meat Sci., 72: 185-194.

S a lga do A., García F on tán M.C., Franco I., Ló pe z M., C a r ba 11 o J. (2005). Biochemical changes during the ripening of Chorizo de cebolla, a Spanish traditional sausage. Effect of the system of manufacture (homemade or industrial). Food Chem., 92: 413-424.

Serra X., Ruiz-Ramír ez J., Arna u J., Gou P. (2005). Texture parameters of dry-cured ham $m$. biceps femoris samples dried at different levels as a function of water activity and water content. Meat Sci., 69: 249-254.

S paziani M., Del Torre M., S te c chin i M.L. (2009). Changes of physicochemical, microbiological, and textural properties during ripening of Italian low-acid sausages. Proteolysis, sensory and volatile profiles. Meat Sci., 81: 77-85.

W ęs i erska E., Palka K., B og dańska J., Chabior K., B arwińska E. (2013 a). Sensory quality of selected raw ripened meat products Acta Sci. Pol. Technol. Aliment., 12: 41-50.

W ęs i erska E., S z ołty s i k M., R a k L. (2013 b). Physico-chemical, biochemical and microbiological properties of traditional Polish pork fermented products during ripening. Food Bioprocess Tech., 6: 2986-2995.

W ęs i erska E., Szołty s ik M., Migdał W. (2014). The properties of fermented beef products ripened as entire primal cuts of $m$. semitendinosus, $m$. semimembranosus and mm. psoas major and minor. Ann. Anim. Sci., 14: 197-212.

Wys zecki G., Stiles W.S. (1982). Colour science. Concepts and methods quantitative data and formula. New York, USA, John Wiley, 2nd ed.

Received: 4 XI 2013

Accepted: 15 IV 2014 